\title{
ЦИФРОВИЗАЦИЯ В ГОСУДАРСТВЕННОМ УПРАВЛЕНИИ НЕДВИЖИМЫМ ИМУЩЕСТВОМ ОРГАНИЗАЦИЙ
}

\author{
(c) 2019 Горбашко Елена Анатольевна \\ доктор экономических наук, профессор \\ Проректор по научной работе, зав. кафедрой проектного менеджмента и управления качеством \\ Санкт-Петербургский государственный экономический университет \\ 191023, Санкт-Петербург, ул. Садовая, 21 \\ ( 2019 Камынина Надежда Ростиславовна \\ кандидат технических наук, доцент \\ доцент кафедры земельного права и государственной регистрации недвижимости \\ Московский государственный университет геодезии и картографии \\ 105064, Москва, Гороховский пер., 4 \\ E-mail: kamyninan@gmail.com
}

В настоящем исследовании обобщены направления, мероприятия, международный опыт и перспективы цифровизации государственного управления недвижимым имуществом организаций (НИО) в аспекте повышения его качества. В частности, для повышения качества госуправления НИО обоснована необходимость включения информационной базы характеристик и показателей комплексной полезности госуправления НИО в постановку задач при разработке и реализации IT-проектов, которая позволит повысить качество интеллектуального анализа при принятии управленческих решений в сфере госуправления НИО.

Ключевые слова: циифровизация, модернизация, качество государственного управления недвижимым имуществом.

В настоящее время в ракурсе государственной стратегии цифровизации экономики автоматизация процессов управления недвижимым имуществом организаций (НИО) становится приоритетным направлением, обеспечивающим качество госуправления в целом. Это, в свою очередь, определяет необходимость разработки и внедрения цифровых проектов в госуправление НИО, соответственно, требует учитывать постулаты теории и практики управления качеством.

Цифровизация государственного управления НИО направлена, в первую очередь, на повышение качества принимаемых управленческих решений в секторе недвижимости за счет использования цифровых технологий, а также на увеличение скорости, качества и охвата оказания услуг, скорости изменений, вносимых в процессы оказания государственных услуг в сфере недвижимого имущества (НИ), и в целом снижение государственных управленческих расходов.

По материалам исследований Бостонской консалтинговой группы предполагаемые результаты от цифровизации госуправления представлены в табл. [9].

На основании этого, можно сделать вывод, что особо ценным является международный опыт цифровизации в сфере управления недвижимым имуществом, показывающий ис-

Таблица. Прогнозы результатов цифровизации в государственном управлении [9]

\begin{tabular}{|c|c|c|c|}
\hline & 2017 & 2018 & 2019 \\
\hline $\begin{array}{l}\text { Количество государственных услуг для бизнеса в электронном виде, } \\
\text { млн. шт. в год }\end{array}$ & 2,028 & 2,253 & 2,504 \\
\hline $\begin{array}{l}\text { Количество освобожденных благодаря цифровизации часов, } \\
\text { млн. часов в год }\end{array}$ & 17 & 22 & 34 \\
\hline $\begin{array}{l}\text { Экономия затрат государства и бизнеса благодаря цифровизации госуслуг, } \\
\text { трлн. руб. в год }\end{array}$ & 2,85 & 3,87 & 5,71 \\
\hline - экономия затрат государства & 0,21 & 0,22 & 0,23 \\
\hline - экономия затрат бизнеса & 2,63 & 3,65 & 5,48 \\
\hline
\end{tabular}


ключительно положительные результаты. Так, например, цифровизация кадастрового учета в странах Западной Европы, США и Канады стала основой информационной базы различных видов реестров (недвижимости, лесного, водного, природоохранного, градостроительного и т.д.). При этом более высокие результаты реализации цифровых проектов продемонстрированы в тех случая, когда регистрационно-учетная информация интегрирована в рамках одной организации. В большинстве экономически развитых зарубежных странах земельный кадастр - это «кадастр недвижимости» вследствие принятого единства судьбы земельного участка и объектов недвижимого имущества, прочно связанных с землей. Данный подход позволяет потребителям цифровых сервисов земельных информационных систем более рационально и экономно осуществлять процедуры передачи прав собственности на НИ, а субъектам госуправления НИО - эффективнее управлять процессами в секторе НИ страны [2].

Согласно экспертным мнениям, достигнуть реализацию программы «Цифровая экономика в РФ» в госуправлении НИ возможно за счет проведения следующих мероприятий:

1. Цифровой приватизации, направленной на высвобождение ресурсов посредством исключения малоэффективных объектов за счет оперативного связывания и сопоставления данных о работе управляемого объекта и последующего принятия управленческих решений в отношении целесообразности его использования. Данное мероприятие позволит повысить эффективность госуправления НИО в зоне коммунальной инфраструктуры, ЖКХ, строительстве и т.п. Здесь интересен опыт внедрения национальной сенсорной сети для построения «умного города», позволяющей оптимизировать процесс управления городским хозяйством за счет видеоаналитики.

2. Цифровизации государственного управления, способствующей повышению эффективности и прозрачности всех процессов взаимодействия с государством и упрощающей ведение бизнеса в стране. В этой связи цифровизация госуправления НИО предполагает, во-первых, перевод документации и системы документационного учета в цифровой формат с использованием режима реального времени и на этой основе реструктуризацию управленческих процессов с точки зрения их эффективности. Во-вторых, позволяет скоординировать работу субъектов госуправления НИО макро-, мезо-, микроуровней в единой системе, а также обеспечить платформенное управление, интегрирующее информационные ресурсы органов власти.

3. Интенсивного внедрения цифровых технологий: больших данных, искусственного интеллекта, нейронных сетей, блокчейна при активном инвестиционном участии государства с целью создания благоприятных условия для ведения бизнеса.

4. Цифрового реинвестирования, при котором предполагается реализовать мероприятия в сфере образования и переквалификации кадров, инфраструктуры, здравоохранения, направленные на создание перспективных условий для развития цифровой экономики и повышение качества жизни населения, что, в свою очередь, предполагает и существенные межотраслевые эффекты [8].

В настоящее время в государственном управлении НИ РФ используются федеральные, региональные, муниципальные информационные системы. Полный перечень информационных технологий и массовых коммуникаций опубликован на официальном сайте «Открытые данные России» [6], где представлены федеральные государственные информационные ресурсы включающие: Единый государственный реестр прав на недвижимое имущество и сделок с ним (ЕГРП), включающий сведения о действующих и прекращенных правах на объекты недвижимого имущества и Государственный кадастр недвижимости ГКН, который является федеральным государственным информационным ресурсом. Его основное назначение - это организация оборота прав зарегистрированных в ЕГРП. Государственный кадастр недвижимости (ГКН), учитывающий объекты недвижимости, представляет собой систематизированный набор сведений об учтенных объектах недвижимости, а также данные о границах Российской Федерации между территориальными образованиями. Автоматизированная информационная система государственного кадастра объектов недвижимости (АИС ГКН) объединяет систематизированную информацию о НИ, а также сведения о прохождении Государственной границы Российской Федерации, о границах между субъектами Российской Федерации, границах муниципальных образований и населённых пунктов, о территориальных зонах и зонах с особыми условиями 
использования территорий и иных предусмотренных Ф3 «О государственном кадастре недвижимости» сведений [1]. АИС ГКН функционирует через Интернет при помощи портальной технологии.

Дополнительно для государственной регистрации прав и кадастрового учета объектов недвижимости используются Программный комплекс ИС Единого государственного реестра прав на недвижимое имущество и сделок с ним (ПК ИС ЕГРП), автоматизирующий ведение ЕГРП, выдачу информации из ЕГРП, формирование выходных документов и статистических отчетов.

Данные информационные системы автоматизируют операции государственной peгистрации прав на НИ и сделок с ним, а также обеспечивают совместимость различных регистрационных информационных систем, применяемых в субъектах РФ.

В настоящее время Росреестр осуществляет централизованное ведение ГКН, при котором процесс постановки на кадастровый учет, ведение ГКН происходят на уровне субъекта РФ, а прием документов на проведение действий, связанных с государственным кадастровым учетом, выдачей документов после осуществления учетных действий - в территориальных отделах, подведомственных Росреестру, по субъектам Российской Федерации и в офисах приема посредством применения системы «Программный комплекс приема-выдачи документов» (ПК ПВД) [8].

Для исключения дублирования, повышения достоверности информации и оптимизации ее хранения, а также увеличения доходной части бюджетов за счет расширения налогооблагаемой базы Росреестром проводятся работы по синхронизации ЕГРП и ГКН. В будущем информационные ресурсы должны быть объединены в Единый государственный реестр недвижимости [4].

Для реализации поставленных целей цифровизации госуправления НИО на макроуровне и мезоуровне применяются технологии: системы электронного документооборота ВРМ-системы управления процессами государственных организаций, облачное хранение данных, интеллектуальные интерфейсы взаимодействия с заявителями при предоставлении государственных услуг, государственные приложения на основе блокчейна, системы мониторинга общественных настроений, интегрирующие различные источники данных, интеллектуальные программы-помощники, решающие задачи для граждан и бизнеса на основе профиля в государственных информационных системах [4].

Для повышения эффективности использования информации о НИО Росреестром внедрен цифровой проект для разбора и обработки информации, а также сопоставления их с данными, содержащимися в реестре федерального имущества (РФИ). Данный проект обладает механизмами аналитической обработки информации, позволяющих снизить количество ошибок в данных и проводить планомерную работу по актуализации сведений $[1,4]$.

Одновременно ведется разработка цифрового проекта интегрированной информационной системы, обеспечивающей обмен данными между субъектами госуправления НИО посредством инструментов электронного правительства в режиме онлайн. Планируется разработка системы больших данных для выявления резервов повышения эффективности использования федерального имущества [4].

Следует подчеркнуть, что в РФ создаются следующие государственные фонды пространственных данных:

1) федеральный фонд пространственных данных;

2) ведомственные фонды пространственных данных;

3) фонд пространственных данных федерального органа исполнительной власти, осуществляющего функции по выработке и реализации государственной политики, нормативно-правовому регулированию в области обороны;

4) фонды пространственных данных субъектов Российской Федерации.

В региональные фонды пространственных данных включаются пространственные данные и материалы, полученные в результате выполнения геодезических и картографических работ, организованных органами государственной власти субъектов Российской Федерации или подведомственными данным органам государственными учреждениями. Региональный фонд пространственных данных создается по решению высшего исполнительного органа государственной власти субъекта Российской Федерации [5]. Данные информационные системы значительно расширяют возможности качественного принятия решений в отношении НИ. 
Вместе с тем препятствиями процессов цифровизации в госуправлении НИ выступают следующие факторы:

- отсутствие нормативно-правовой базы цифровизации в управлении недвижимостью;

- разные источники финансирования и непропорциональные ассигнования в мероприятия цифровизации;

- сильная разрозненность субъектов управления НИ, требующая масштабности и сложности процессов цифровизации;

- различие в стандартах ведения документации и внедрения цифровых технологий;

- угрозы киберпреступлений в отношении объектов НИ:

- высокая стоимость перевода данных в цифровой вид;

- неподготовленность и низкая мотивация государственных служащих;

- технологическое отставание в использовании экспертных систем при принятии решений, а также технологий блокчейн $[9,10,11]$.

На основании вышесказанного для активизации процессов цифровизации в госуправлении НИО необходимо применение интеллектуальных систем экспертной обработки информации на базе современных программных комплексов. Для реализации Программы «Цифровая экономика» Центром стратегических разработок уже предложена идея «Государство как Платформа», в которой, по мнению авторов, цифровая трансформация госуправления должна строиться на целевой основе повышения качества, результативности, удовлетворенности потребителей, где ключевым фактором является благополучие граждан и экономический эффект [7]. В рассматриваемом сценарии предполагается сформировать сервисную экосистему цифрового государства, в основе которой лежит архитектурное построение, включающее подход к реализации цифровизации госуправления по аналогии с ИТ-компаниями. В частности, разработан проект «Государственная Цифровая Платформа (ГЦП)», создающий единую программно-аппаратную среду, поддерживающую алгоритмизированные взаимоотношения значимого количества участников (государства, граждан, бизнеса), а также обеспечивающий их интегрированными бизнес-процессами, сервисами, информацией и аналитикой. По мнению разработчиков, использование ГЦП приведет к снижению транзакционных издержек и пре- доставит возможность для подключения новых участников (посредством API и др.)[7]. При создании цифровой экосистемы планируется увеличить функциональность посредством добавления новых данных и сервисов, замещающих существующие системы [7].

С целью совершенствования госуправления НИО следует, прежде всего, обеспечить единство информационного пространства, что позволит объединить все уровни и элементы системы управления НИО и повысить не только скорость и эффективность управленческих решений, но и качество госуправления в целом. В этом аспекте важна информационная система (база данных), отражающая параметры процессов и их изменений в управляемой системе НИ, а также необходимая при разработке управленческих воздействий, направленных на достижение главной цели государственного управления НИО, поскольку качество информационного обеспечения является необходимым условием устойчивого и эффективного функционирования любых систем управления и является одним из составляющих качества госуправления НИО.

В практике реализации цифровых проектов применительно к сложным экономическим объектам используется методология построения моделей архитектуры объекта, действующей в качестве платформы для будущей цифровой системы данного объекта. При этом под архитектурой объекта (организации) понимается процесс изображения ключевых составляющих бизнес-системы, которые описывают его будущее состояние и делают возможным его развитие, в частности, включает набор принципов, методов и моделей, используемых для проектирования и реализации организационной структуры бизнес-процессов в будущей информационной системе [1].

В связи с этим построение архитектуры госуправления НИО с целью дальнейшей разработки цифровых решений как одного из секторов госуправления, необходимо осуществлять в контексте повышения его качества, целостности системы госуправления НИО, ее субъектно-объектного состава, взаимосвязей процессов, целей, показателей качества результатов в целом. Соответственно, автором предлагается следующая концептуальная платформа цифровизации госуправления НИО для повышения его качества (рисунок). 
Государственная стратегия

Государственные программы по управлению НИО

Цель, задачи госуправления НИо

Результаты госуправления НИО: оптимальная структура НИО, качественная информационная база данных о НИО, госуслуги в сфере НИО, удовлетворяющие своим качеством потребителей

Управленческие функции: прогнозирование, планирование, координация, учет, регулирование, мотивация, контроль

Принципы TQM

Принципы управления НИ

Принципы цифровизации экономики

Субъекты госуправления НИо: Государственные федеральные органы и структурные подразделения Правительства, государственные и муниципальные органы регионов, собственники и управляющие организации

Объекты НИо: недвижимое имущество макро-,мезо-, микроуровней

Потребители госуправления НИО: собственники НИ, организации и сообщества, государство, международное сообщество

Процессы: использование в производстве, аренда, продажа, лизинг ит.п.

Услуги: кадастровый учет, регистрация прав и сделок с НИ

Показатели качества госуправления НИО: комплексная полезность: удовлетворенность заинтересованных сторон; рост полезности национального имущества

Результаты повышения качества госуправления НИО: рост экономических показателей использования НИ, экономическое и социальное развитие экономики РФ

Рис. Концептуальная платформа цифровизации госуправления НИО в аспекте повышения его качества. 
Таким образом, концептуальная платформа включает элементы:

1. Цели госуправления НИО - экономические, социальные, экологические, технологические, которые, в свою очередь, складываются в дальнейшие задачи:

- Создание информационно-аналитической базы для принятия адекватных управленческих решений в сфере недвижимости.

- Оптимизация распределения объектов недвижимости по типам использования (операционная, инвестиционная).

- Формирование стратегий и программ управления недвижимостью.

- Надлежащая техническая эксплуатация и обслуживание объектов недвижимости.

- Обеспечение функционирования систем безопасности объектов недвижимости.

- Эффективное продвижение объектов недвижимости на рынок.

- Ведение мониторинга за состоянием объектов недвижимости с целью оперативного принятия управленческих решений.

- Минимизация затрат на содержание системы управления недвижимым имуществом.

- Повышение качества и объемов услуг клиентам - жильцам, арендаторам и покупателям.

- Обеспечение эффективного взаимодействия с органами власти.

- Поддержка положительного имиджа в обществе и целевых социальных группах.

2. Результаты госуправления НИО: оптимальная структура НИО, качественная информационная база данных о НИО, госуслуги в сфере НИО, удовлетворяющие своим качеством потребителей, денежный прирост бюджета от функционирования НИО.

3. Принципы TQM, принципы управления НИО, отраженные в Постановлении Правительства РФ от 15 апреля 2014 г. № 327 «Об утверждении государственной программы Российской Федерации «Управление федеральным имуществом», принципы цифровой экономики согласно Программе «Развитие цифровой экономики в России до 2035 г.».

4. Совокупность объектов и субъектов НИО макро-, мезо-, микроуровней госуправления НИО.

5. Потребителей госуправления НИО: собственники НИ, организации и сообщества, государство, международное сообщество.

6. Процессы в отношении НИО: использова- ние в производстве, аренда, продажа, лизинг и Т.П.

7. Услуги: кадастровый учет, регистрация прав и сделок с НИ.

8. Показатели качества госуправления НИО: комплексная полезность; удовлетворенность заинтересованных сторон; рост полезности национального имущества.

9. Результаты повышения качества госуправления НИО, в частности, рост экономических показателей использования НИ, экономическое и социальное развитие экономики РФ, повышение уровня конкурентоспособности РФ.

Одновременно при разработке цифровых проектов для госуправления НИО целесообразно создать информационную базу характеристик и показателей комплексной полезности госуправления НИ, позволяющую формировать цифровые модели управляемых ситуаций с учетом субъектно-объектного состава, взаимосвязи процессов в секторе НИ, целей, показателей качества и результатов госуправления в целом. Это позволит повысить информационную обеспеченность управленческих действий в отношении НИО.

Таким образом, цифровизация госуправления НИО предполагает масштабную трансформацию информационной системы госуправления РФ, включающую и сектор НИО, а также внедрение технологий блокчейна, больших данных и др. С целью обеспечения качества госуправления НИО при формировании исходных позиций цифровых информационных платформ необходимо руководствоваться управленческими концептами качества. Для повышения эффективности управленческих решений в условиях цифрового пространства госуправления НИО ГЦП должна содержать информационную базу характеристик и показателей комплексной полезности госуправления НИ.

Резюмируя исследование, следует подчеркнуть, что цифровизация госуправления НИО должна опираться на критерии и показатели его качества, что позволит повысить объективность принимаемых решений в отношении НИ. Следовательно, цифровые аналитические экспертные системы принятия решений должны включать информационную базу характеристик и показателей комплексной полезности госуправления НИ, что будет являться исходным условием для разработки и реализации IT-проектов в сфере госуправления НИ. 


\section{Библиографический список}

1. Информационные технологии в государственном и муниципальном управлении: учебное пособие для бакалавриата и магистратуры / О.А. Морозова, В.В. Лосева, Л.И. Иванова.- 2-е изд., испр. и доп.- М.: Издательство Юрайт, 2018. - 142 с.

2. амынина Н.Р. Концептуальная модель информационного обеспечения кадастрового учета недвижимости в Российской Федерации. Автореферат дис. ... кандидата технических наук 25.00.26, Моск. гос. ун-т геодезии и картографии, Москва, 2013.

3. Макареня Т.А, Быстрая Ю.С. Архитектура предприятия: инструмент решения противоречий управления предприятием//Государственное и муниципальное управление. Ученые записки СКАГС.- 2015. -№ 4.С.48-52.

4. Официальный сайт. Росреестр. Начальник Управления информационных технологий Росимущества Александра Осипова приняла участие в конференции IT Government Day 2018. Пресс-релиз от 01.03.2018. -URL: https://www.rosim.ru/press/news/326931 (дата обращения: 09.10.18).

5. Официальный сайт. Росреестр. Инфраструктура пространственных данных РФ.- URL: https://rosreestr.ru/ site/activity/infrastruktura-prostranstvennykh-dannykh-rossiyskoy-federatsii/ (дата обращения: 09.10.18).

6. Официальный сайт. Открытые данные России.- URL: https://data.gov.ru/opendata/7708660670-reestr-fgis (дата обращения: 11.10.18).

7. Петров М., Буров В., Шклярук М., Шаров А. Государство как платформа. (Кибер) Государство для цифровой экономики. Цифровая трансформация. [Электронный ресурс]. Москва. 2018. 52 c.-URL:: https://www.csr.ru/ wp-content/uploads/2018/05/GOSUDARSTVO-KAK-PLATFORMA_internet.pdf. (дата обращения: 09.10.18).

8. Программа «цфровая экономика Российской Федерации»: распоряжение Правительства Российской Федерации от 28 июля 2017 года № 1632-p.-URL: http://static.government.ru/media/files/9gFM4FHj4PsB79I5v7y LVuPgu4bvR7M0.pdf (дата обращения: 09.10.18).

9. Россия онлайн: четыре приоритета для прорыва в цифровой экономике / Степаненко А., Банке Б., Бутенко B. [и др.]. [Электронный ресурс]. - The Boston Consulting Group.-Октябрь, 2017. - 28 c. -URL: http://imagesrc.bcg.com/Images/Russia-Online_tcm27-178074.pdf (дата обращения: 09.10.18).

10. Технологическое будущее российской экономики [Текст]: докл. к XIX пр. междунар. научн. конф. по проблемам развития экономики и общества, Москва, 10-13 апр. 2018 г. / гл. ред. Л.М. Гохберг; Нац. исслед. ун-т «Высшая школа экономики».- М.: Изд. Дом Высшей школы экономики, 2018. - 193 с.

11. Цифровая экономика: краткий статистический сборник / Г.И. Абдрахманова, Л. М. Гохберг, А. В. Демьянова и др.; Нац. исслед. ун-т «Высшая школа экономики».- М.: НИУ ВШЭ, 2018. - 96 с. URL: https://issek.hse.ru/ data/2018/07/27/1152150310/ice2018kr.PDF (дата обращения: 11.10.18). 